\title{
SELECIONANDO UM ENTERPRISE RESOURCE PLANNING (ERP) A PARTIR DO MÉTODO HÍBRIDO AHP-TOPSIS-2N
}

\author{
Rachel Medina Trindade (UNIGRANRIO) rachelmedinatrindade@gmail.com \\ Thays Marques Rodrigues (UNIGRANRIO) thaysmarquess@ hotmail.com \\ Angélica Rodrigues de Lima (IME) angeliquinha.lima@gmail.com \\ Carlos Francisco Simões Gomes (UFF) cfsg1@bol.com.br \\ Prof. Dr. Marcos dos Santos (Instituto Militar de Engenharia - IME) \\ marcosdossantos_doutorado_uff@yahoo.com.br
}

\section{Resumo}

O presente estudo tem como objetivo selecionar um ERP a partir da aplicação do método de apoio a decisão multicritério AHP TOPSIS $2 \mathrm{~N}$ para uma fábrica produtora de tortas localizada na cidade do Rio de Janeiro. A seleção do sistema ERP contribuirá para que a empresa consiga unificar os dados dos processos e proporcionar uma significativa melhora na gestão dos negócios. Um sistema Enterprise Resource Planning (ERP) tem o objetivo de amparar e unir informações de toda a empresa. O compartilhamento de informações entre o chão de fábrica e os sistemas de gestão pode permitir que os fabricantes alcancem novos níveis de eficiência. O ERP contribui para definir padrões que serão aplicados. Ajuda, de modo especial, na centralização das informações da fábrica em apenas uma fonte de dados, a partir da qual são geradas informações para diferentes setores; essa estratégia reduz a margem de erros, pois todas as informações estarão integradas entre si, o que facilita a análise e a tomada de decisões. Uma das mais importantes vantagens do ERP é que permite a integração entre todos os setores, tornando mais fácil a gestão de produção, integrando máquinas, identificando e tratando os pontos mais graves, ajudando a reduzir custos e estoques, monitorar refugos e aprimorar os prazos de entrega.

Palavras-Chaves: Apoio Multicritério à Decisão (AMD); Método AHP-TOPSIS-2N; Enterprise Resource Planning (ERP).

\section{Introdução}

O cenário de globalização e o avanço da tecnologia tornaram o mercado ainda mais competitivo, despertando a atenção das micro e pequenas empresas para o investimento em recursos que possibilitam o crescimento e aumento da competitividade. Sendo assim, investir em um sistema de gestão, como os softwares, é bastante relevante para os empresários, pois 
proporciona o controle eficiente das tarefas financeiras, fluxos de trabalho, gestão de entrega, gestão de estoque e outros elementos que estão presentes nas atividades da empresa.

Mendes (2007) define um ERP (Enterprise Resource Planning) como a combinação das práticas, procedimentos e processos utilizados em uma empresa ou organização para implantar suas políticas de gestão, de modo a ser mais eficiente na obtenção e alcance dos objetivos proveniente delas do que quando há diversos sistemas individuais atuando ao mesmo tempo.

Na visão de Moraes et al, (2004), o ERP é uma ferramenta de suporte à gestão da informação na pequena empresa, pois ele possibilita a automatização de tarefas, auxiliando o controle das operações, coletando e fornecendo dados e informações em tempo real e, desse modo, auxiliando a tomada de decisão e gerenciamento estratégico do negócio, aumentando a capacidade dos gerentes e administradores da empresa de encontrar e resolver antecipadamente os problemas referentes a processos, operações e planejamento da empresa.

O ERP auxilia a empresa na redução de custos e obtenção de lucro, gerando um ganho de produtividade, visibilidade da empresa pelo mercado, uma forma mais eficaz de relacionamento com clientes e fornecedores, e mais uma série de fatores que, conjuntamente, geram o crescimento da empresa e consolidam sua marca no mercado.

Dentro desse contexto, o presente estudo irá selecionar, por meio da aplicação do método de apoio à decisão multicritério AHP TOPSIS 2N, um sistema ERP (Enterprise Resource Planning) que atenda e seja adequado às necessidades operacionais de uma pequena fábrica de tortas localizada na cidade do Rio de Janeiro.

\section{Descrição do problema}

O presente trabalho estuda o problema da empresa de pequeno porte chamada Fábrica de Tortas Nene, localizada em Mesquita, na baixada do Rio de Janeiro. A fábrica produz tortas e bolos, e contém uma cartela de clientes e revendedores obtendo produção sobre pedido realizado, a mesma contém uma deficiência na gestão de estoque que prejudica na produção e no controle dos materiais em estoque.

Em pequenas empresas, ainda é comum à utilização de planilhas para o controle de finanças e estoques. Tal método funciona enquanto a empresa dá seus primeiros passos, mas se mostra deficitário conforme a evolução do negócio, contando que as contratações e o volume de 
operações aumentam e então começa a ocorrer divergências entre números financeiros, produção, estoque e gestão. Os riscos e impactos com esse método de controle podem ser agudos e críticos, trazendo problemas como: perda de documentos e informações importantes, multas por falta de organização, falta de uma visão consolidada dos processos da empresa (o que limita o crescimento), perda de insumos por deficiências no controle do estoque, perda de tempo para tentar localizar onde estão as falhas que levaram a esses problemas e, sobretudo, problemas na tomada de decisão.

Com essa forma de controle, o gestor apenas terá informações competitivas e importantes se os dados se mantiverem organizados e interligados entre si. A integração facilita o acesso aos dados de diferentes áreas e oferece maior transparência no diagnóstico e tomada de decisão. Baseado nisso, um sistema integrado traria maiores benefícios para a empresa e também ajudaria o gestor a manter a ordem e o controle.

Em um negócio, a falta de controle pode ser o causador de muitos problemas que afetam o crescimento e faturamento da empresa. Quando não há controle dos materiais, se torna mais difícil planejar a aquisição dos mesmos, o que torna vulnerável à compra dos insumos no varejo afetando diretamente a margem de lucro dos produtos finais. Além de ocasionar a falta de certos materiais, expondo a fábrica a pedidos que não poderão ser atendidos. Desta forma, o cliente insatisfeito irá preferir comprar em concorrentes. Podemos citar também, os produtos obsoletos que por estar a muito tempo em estoque, podem estar com prazos de validade vencidos, e a utilização destes produtos submete a organização a ações judiciais.

A Nene Tortas, por ser uma fábrica de pequeno porte onde não se encontra uma gestão capaz controlar com eficiência o estoque de insumos, está vulnerável a tais problemas. A Figura 1 a seguir expõe de maneira mais clara todos os problemas que a empresa enfrenta. 


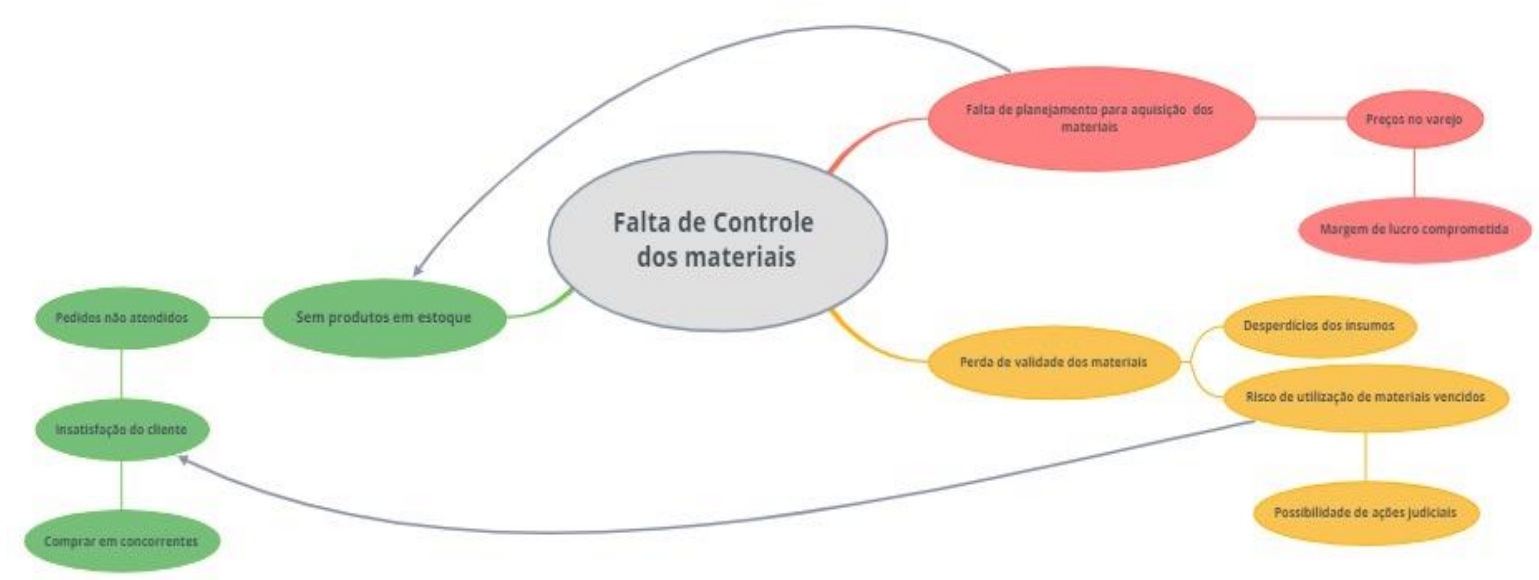

Fonte: Autores (2019)

Santos et al. (2013) afirmam que a Pesquisa Operacional (PO) lança mão de modelos matemáticos e/ou lógicos, com o objetivo de resolver problemas de dentro das organizações, apresentando um caráter eminentemente multidisciplinar. A escolha de um software corporativo pode tornar-se uma tarefa árdua para o gestor de uma pequena fábrica que ainda não compreende quais as funcionalidades o ERP deve obter para o sucesso do negócio. Afinal, o sistema ERP deve estar alinhado aos objetivos e ao perfil do empreendimento, permitindo que suas funções se integrem cada vez mais à cadeia operacional e, com isso, facilitando a criação de fluxos de trabalho mais ágeis e com menos erros.

\section{Fundamentação teórica}

\subsection{Enterprise resource planning (ERP)}

De acordo com Souza (2000), Enterprise Resource Planning (ERP) são sistemas de informação integrados que tem o objetivo de dar suporte a maioria das operações de uma empresa e são geralmente divididos em módulos que se comunicam e atualizam uma base de dados central, que envolve diversos setores, de modo que a informação que foi alimentada em um módulo é disponibilizada para os módulos que dela depende, instantaneamente. Os sistemas ERP permitem ainda a utilização de ferramentas de planejamento que podem analisar o impacto de decisões de produção, matéria prima, finanças ou recursos humanos em toda empresa. 
O ERP é um software que permite a integração das informações que surgem pela empresa, esse sistema determina sua própria lógica à estratégia, à cultura e a à organização da instituição. É uma sistemática que procura atender a todo tipo de companhia e seu projeto reflete uma série de possibilidades sobre como operam as organizações e é preparado para desenvolver as melhores práticas de negócio, porém fica a critério do cliente para definir a melhor prática e atender às suas necessidades (DAVENPORT, 1998). Existem áreas específicas que o sistema ERP interliga, na Figura 2 a seguir são apresentadas as áreas de integração do sistema.

Figura 2 - Integração entre as principais áreas de uma empresa

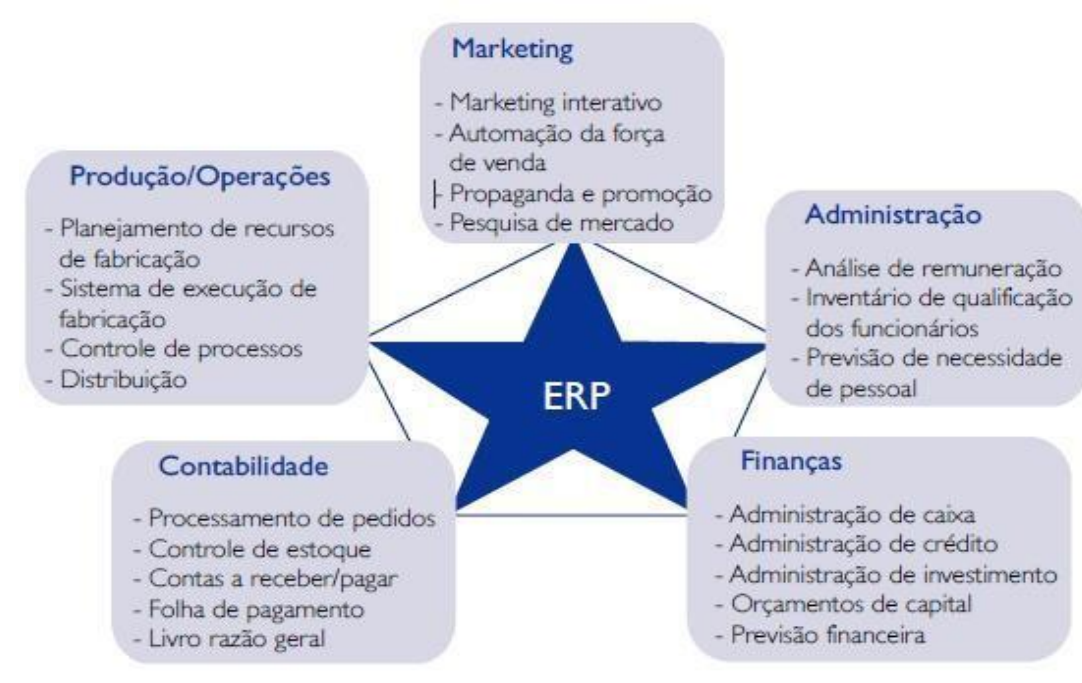

Fonte: O’Brien (2007)

Colangelo Filho (2001) também define as principais áreas de aplicação dos sistemas ERP, que são: Finanças e Controles (Contabilidade financeira, contas a pagar, contas a receber, ativo imobilizado, orçamentos, contabilidade gerencial, custos e análise de rentabilidade), Operações e Logísticas (Suprimentos, administração de materiais, gestão da qualidade, planejamento e controle de produção, Custos de produção, previsão de vendas, entrada de pedidos, faturamento, gestão de projetos) e Recursos Humanos (Recrutamento e seleção de pessoal, treinamentos, benefícios, desenvolvimento pessoal, medicina e segurança do trabalho, remuneração e folha de pagamento.

\subsection{Pesquisa operacional e apoio à decisão}

A Pesquisa Operacional é uma ferramenta matemática que auxilia no processo de tomadas de decisão em situações reais, é bastante empregada como ferramenta no apoio a decisão quando 
há enfrentamento dos problemas no ambiente de negócios (BARBOSA e ZANARDINI, 2015).

Santos et al, (2016) afirmam que a Pesquisa Operacional atua em cinco grandes áreas que se inter-relacionam, conforme apresentado na Figura 3.

Figura 3 - Áreas da Pesquisa Operacional.

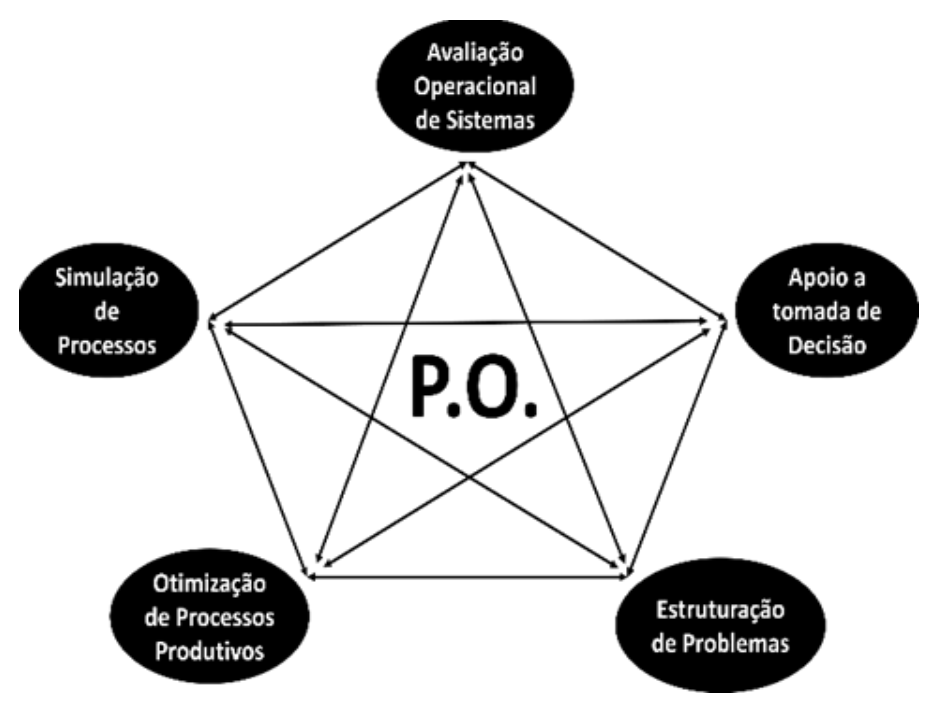

Fonte: Santos et al. (2016)

\subsection{O método AHP TOPSIS 2N}

O Método AHP TOPSIS 2N, nada mais é que a união dos conceitos do Método AHP com o Método TOPSIS.

O Método AHP, criado por Thomas Saaty, é uma ajuda à empresários a tomar decisões importantes para seu negócio, além disso coopera com a seleção e justificativa de escolha. Já o Método TOPSIS, criado por Hwang \& Yoon, que avalia a performance de alternativas sobre as similaridades da mesma com a solução ideal, ou seja, a melhor alternativa é aquela que mais chega perto da solução ideal e a que mais se distância da solução não ideal.

A definição dos pesos para cada critério é realizada através da matriz de ponderação, onde é baseado na Escala de Saaty descrita na Tabela 1 a seguir. 
Tabela 1 - Escala Fundamental de Saaty.

\begin{tabular}{|c|c|c|}
\hline VALOR & DEFINIÇÃO & EXPLICAÇÃO \\
\hline 1 & Igual importância & $\begin{array}{l}\text { os dois critérios contribuem de forma idêntica para } \\
\qquad \text { o objetivo }\end{array}$ \\
\hline 3 & $\begin{array}{l}\text { Pouco mais impor- } \\
\text { tante }\end{array}$ & $\begin{array}{c}\text { a análise e a experiência mostram que um critério } \\
\text { é um pouco mais importante que o outro }\end{array}$ \\
\hline 5 & $\begin{array}{l}\text { Muito mais impor- } \\
\text { tante }\end{array}$ & $\begin{array}{l}\text { a análise e a experiência mostram que o critério é } \\
\text { claramente mais importante que o outro }\end{array}$ \\
\hline 7 & $\begin{array}{l}\text { Bastante mais im- } \\
\text { portante }\end{array}$ & $\begin{array}{l}\text { a análise e a experiência mostram que um dos } \\
\text { critérios é predominante para o objetivo }\end{array}$ \\
\hline 9 & $\begin{array}{l}\text { Extremamente mais } \\
\text { importante }\end{array}$ & $\begin{array}{l}\text { sem qualquer dúvida um dos critérios é absoluta- } \\
\text { mente predominante para o objetivo }\end{array}$ \\
\hline $\begin{array}{c}\mathbf{2 , 4 , 6 , 8} \\
\text { valores reciprocos dos anteriores }\end{array}$ & $\begin{array}{l}\text { Valores intermediá- } \\
\text { rios }\end{array}$ & também podem ser utilizados \\
\hline
\end{tabular}

Fonte: Saaty (1980)

Segundo Souza et al (2018), o passo a passo desse método é baseado em: Definição da Matriz de Decisão, Normalização, Normalização Ponderada, SIP, SIN, cálculos de medidas de distância e proximidade e ordenação.

\section{Estudo de caso}

\subsection{Levantamento de dados}

Na função de ajudar no processo decisório da aquisição de um sistema integrado, utilizou-se o Método AHP TOPSIS 2N embasado em cinco critérios levantados em conjunto com os proprietários:

- Manutenção: Trabalho realizado pela fornecedora do sistema escolhido que garante o funcionamento adequado dele. Essa manutenção pode acarretar novos custos à empresa; (Até R\$270,00)

- Custo do Sistema: É o investimento que a empresa terá para implantar o sistema escolhido. Este custo envolve todas as despesas de pré-implantação; (Até R\$ 1.000,00)

- Suporte: Este critério visa quantificar a qualidade do suporte oferecido, ou seja, tempo para solucionar uma dúvida, nível de resolução de problemas, entre outros; (Min de 24h de atendimento) 
- Aderência: Neste critério se identifica o quão aderente o software será para que se obtenha a satisfação na implementação, isto é, para que se exija menos horas de consultoria especializada; (Implementado completamente em até 2 meses)

- Customização: Se relaciona as atividades realizadas no sistema, antes de sua implementação, com intuito de adequar procedimentos da empresa no mesmo. Através disso, este critério visa quando será necessário mudar cada alternativa. (Mínimo 4 módulos)

Com base no levantamento dos critérios, foi repassado a realidade da empresa para um especialista em sistema integrado e através disso foram definidos os ERP no Quadro 1 a seguir.

Quadro 1 - Descrição dos sistemas integrados escolhidos

SISTEMA

BLING

SAGE X3

SBG

\section{DESCRIÇÃO}

Software direcionado a micro e pequenas empresas que apresentam lojas virtuais, de preço acessivivel a sociedade, sendo este reconhecido pelo segmento de E-business.

Software prestigiado no mercado, bem comum e direcionado para vários segmentos econômicos.

Software destinado a empresas pequenas e grandes, estão há mais 15 anos no mercado, tendo clientes em vários locais no mundo.

Fonte: Autores (2019)

\subsection{Modelagem matemática: método AHP TOPSIS 2N}

Os resultados do método AHP TOPSIS $2 \mathrm{~N}$ foram obtidos a partir de um software desenvolvido em Python por Ribeiro, Santos e Gomes (2019), no Instituto Militar de Engenharia.

A primeira etapa é definir através dos critérios o grau e importância entre cada um. Para a implementação do método faz-se necessária executar a Matriz de Ponderação, apresentada na Figura 4.

Figura 4 - Matriz de Ponderações.

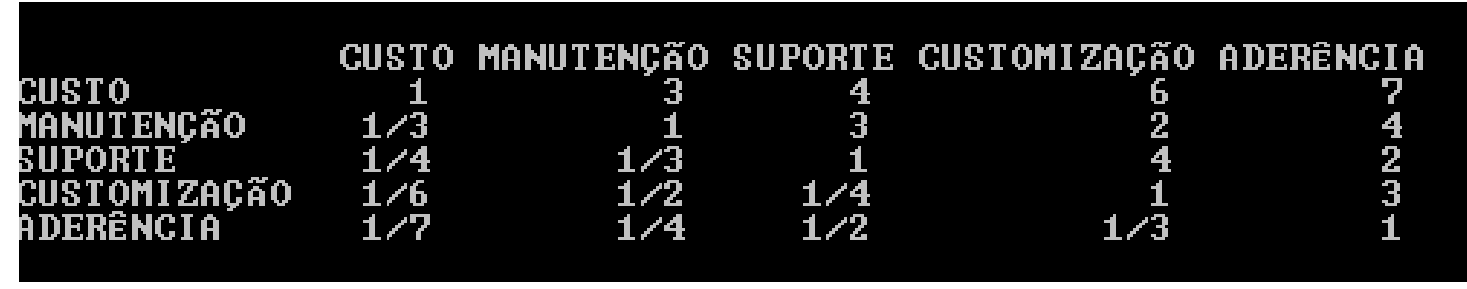

Fonte: Autores (2019) 
Por meio da Matriz de Ponderações são definidos os pesos para cada critério estipulado, assim também como lambda máximo ( $\lambda$ max), o Índice e a Razão de Consistência, apresentados na Figura 5.

Figura 5 - Pesos, Lambda, Índice e Razão de Consistência.

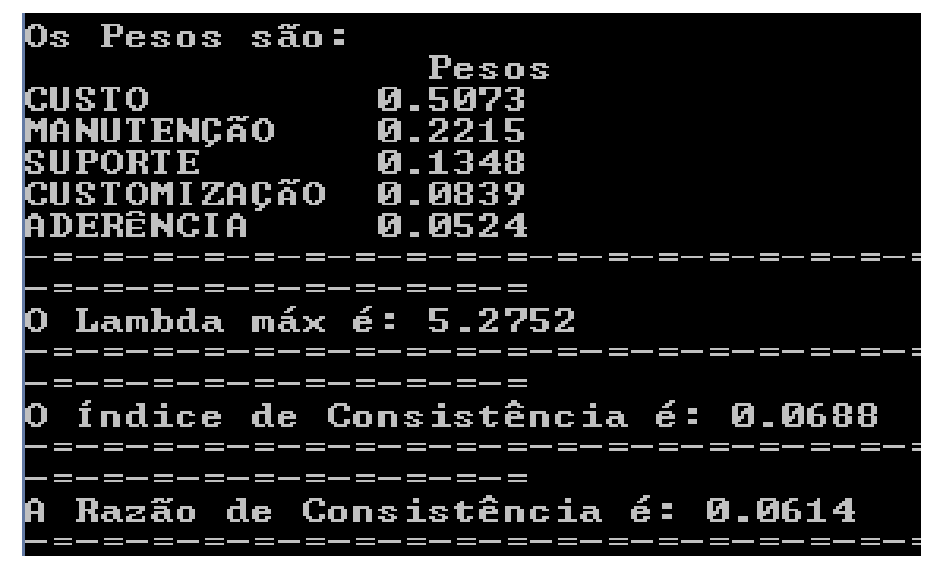

Fonte: Autores. (2019)

Assim, pode-se relacionar a Matriz de Decisão com os valores de cada critério referente à cada alternativa, de acordo com a Tabela 2 a seguir.

Tabela 2: Matriz de Decisão

\begin{tabular}{c|ccccc}
\multicolumn{1}{c}{ PESOS } & $\mathbf{5}$ & $\mathbf{4}$ & $\mathbf{3 . 3 3}$ & $\mathbf{1}$ & $\mathbf{0 . 5}$ \\
\hline CRITÉRIOS & CUSTO & MANUTENÇÃO & SUPORTE & CUSTOMIZAÇÃO & ADERÊNCIA \\
BLING & $\mathrm{R} \$ 300,00$ & $\mathrm{R} \$ 45,00$ & 24 & 20 & 0,25 \\
SAGE X3 & $\mathrm{R} \$ 850,00$ & $\mathrm{R} \$ 250,00$ & 28 & 40 & 1,5 \\
SBG & $\mathrm{R} \$ 720,00$ & $\mathrm{R} \$ 150,00$ & 23 & 15 & 0,75
\end{tabular}

Após, é realizado o processo de normalização das alternativas sobre os critérios atribuídos. Esse processo consiste em duas etapas, como mostra nas Figuras 6 e 7 a seguir. 
Figura $6-1^{\circ}$ Matriz Normalizada e Ponderada

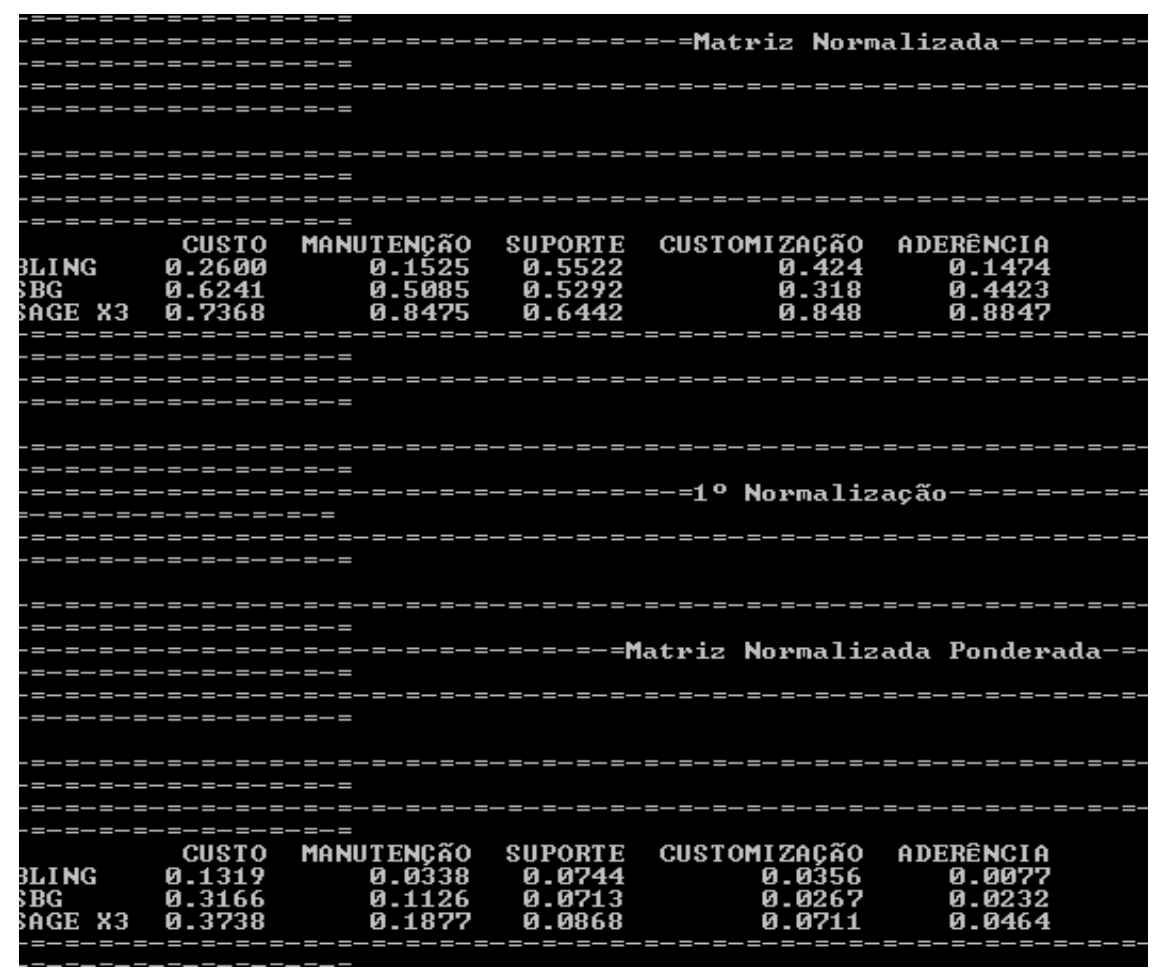

Fonte: Autores (2019)

Figura $7-2^{\circ}$ Matriz Normalizada e Ponderada

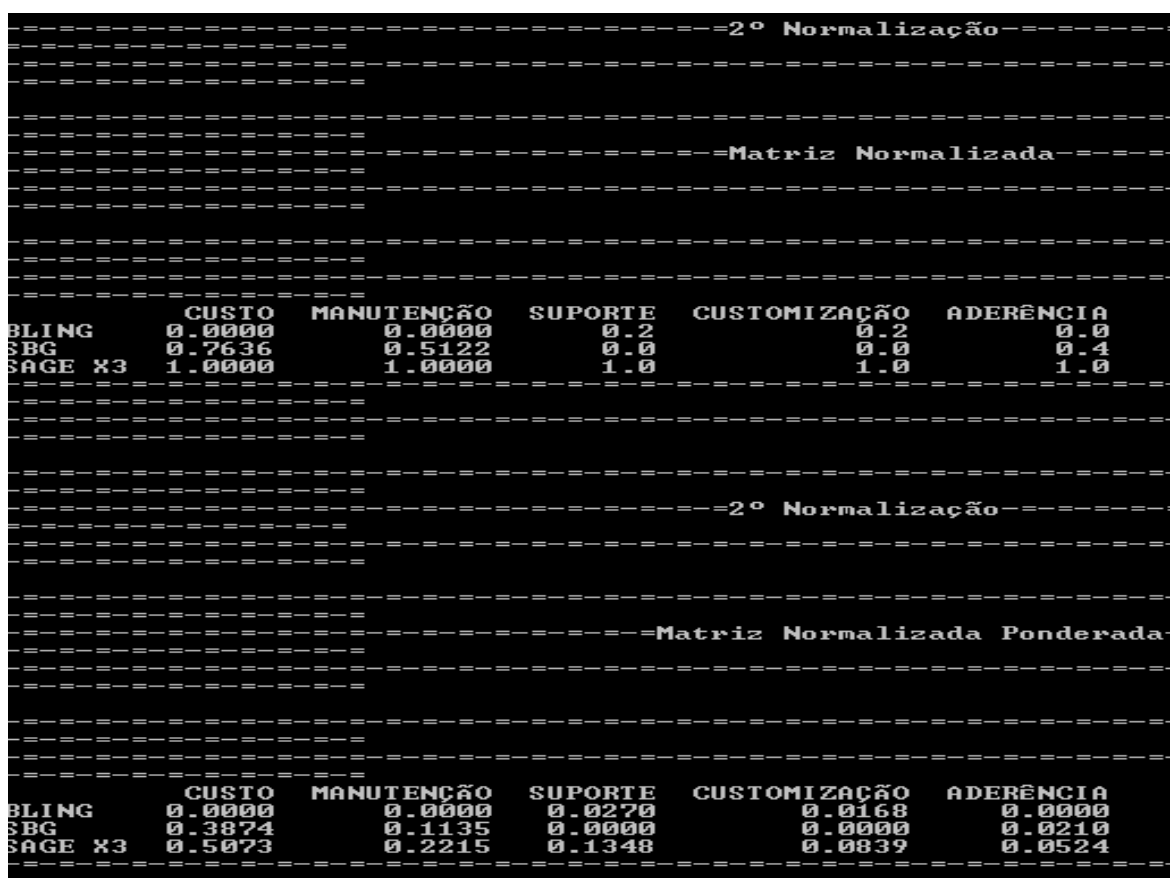

Fonte: Autores (2019)

Depois dessas etapas, entra o processo de solução ideal, onde é definido a alternativa ideal positiva e negativa. Essa definição vem de concluir qual é o Mínimo e o Máximo de cada critério de preferência, como mostra a Figura 8. 
Figura 8 - Definição dos parâmetros para a Solução Ideal Positiva e a Solução Ideal Negativa

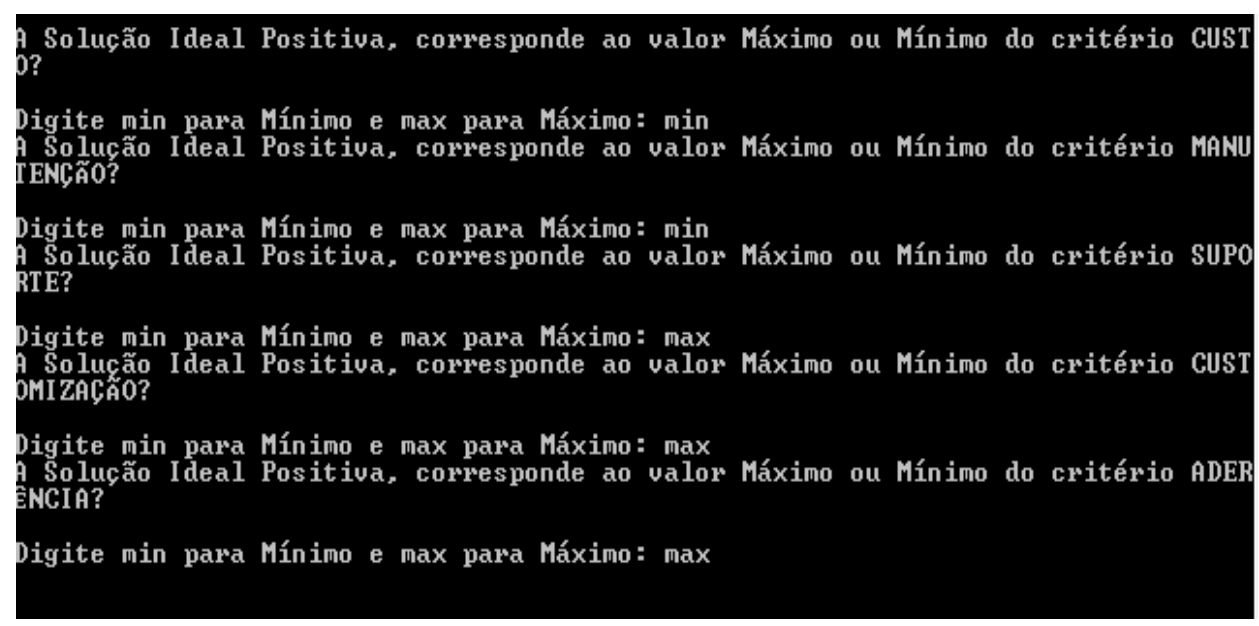

Fonte: Autores (2019)

Nessa etapa, os cálculos mostram qual é o melhor valor em relação aos critérios, sendo como exemplo o máximo do critério "custo" o menor valor estipulado e assim por diante.

O último passo é fazer o ranqueamento das alternativas mais ideais que também são divididas em duas etapas de normalização e através disso conseguimos obter a pontuação de desempenho de cara alternativa, sendo escolhida a que melhor atende, conforme Figura 9.

Figura 9 - Ranking dos resultados.

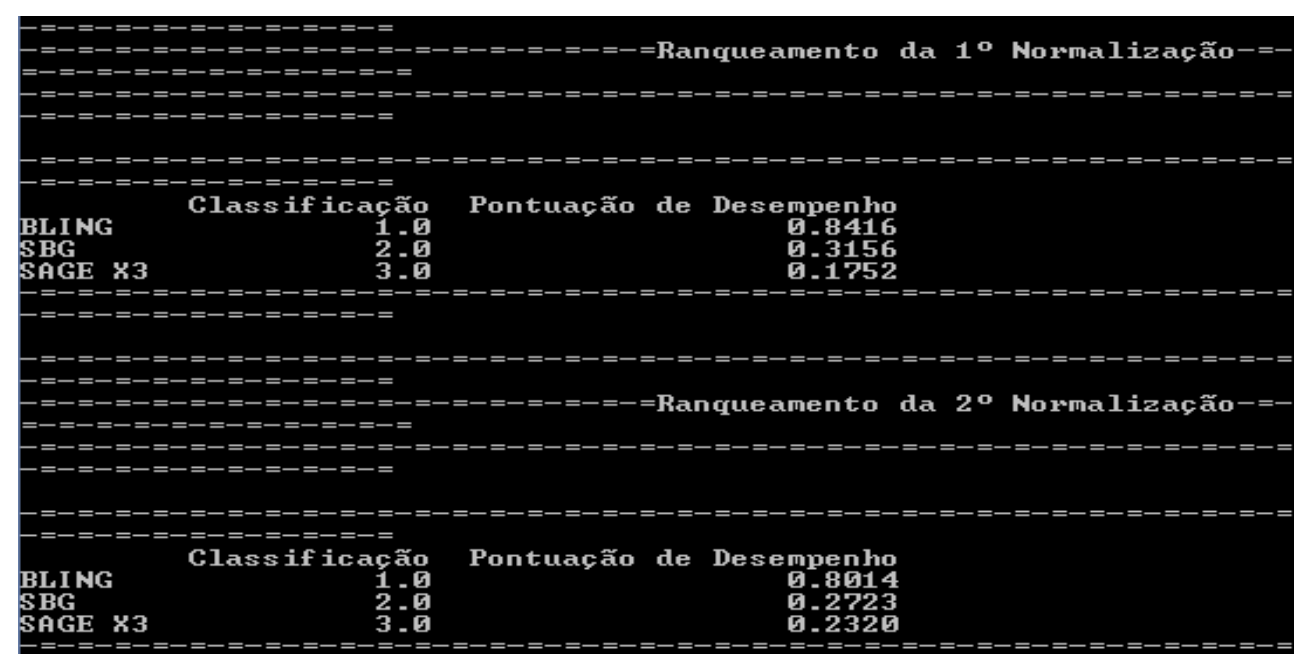

Figura: Autores (2019) 


\section{Resultados e discussões}

Conforme os resultados, SAGE X3 apresentou pouca significância para o negócio estudado, mesmo sendo ele totalmente direcionado para diversos segmentos e tendo uma relevância significativa para setores comerciais, facilitando formas de vendas e pagamentos. Porém foram atribuídos pesos maiores para os critérios de custo de aquisição e manutenção, por isso a perda do SAGE X3 foi notória desde o início por apresentar o maior custo dentre os dois critérios.

Baseado ainda nos resultados, o SBG obteve um resultado intermediário, apesar de ser utilizado em microempresas e até em multinacionais, porém ainda assim esse sistema apresenta um alto custo de aquisição para a empresa e apesar de ter um custo menor de manutenção que o SAGE X3, ainda assim, com os maiores pesos sendo em manutenção e custo de aquisição, ele não teve um resultado esperado, porém seria uma $2^{\circ}$ opção para a empresa.

Com base nas discussões, pode-se considerar que o BLING foi o sistema que melhor se adequou aos critérios pontuados pelos decisores. Por ser uma empresa de pequeno porte e em crescimento, esse software atende bem as necessidades da empresa com relação aos controles importantes para que a mesma consiga se desenvolver e crescer ainda mais.

\section{Considerações finais}

Com base nos fatos expostos, pode-se concluir o quão importante é um método de apoio à decisão para cooperar com a escolha de uma determinada necessidade em uma empresa, sendo este micro, pequeno, médio ou grande porte.

O método de apoio à decisão multicritério AHP TOPSIS $2 \mathrm{~N}$ foi aplicado de modo satisfatório e apoiou totalmente os gestores na tomada de decisão do sistema. O software ERP BLING mostrou-se mais adequado às necessidades da empresa estudada no atual momento da empresa, e como foi abordado no desenvolvimento do estudo, BLING é um ERP voltado à micro e pequenas empresas e possui um baixo custo de aquisição e manutenção, tais critérios foram fortes atrativos para os decisores.

Com a aplicação do método e a utilização da ferramenta desenvolvida pelo IME para a solução do problema, o processo decisório apresentou informações claras facilitando e norteando a tomada de decisão dos gestores. 
Como trabalho futuro, seria de suma importância acompanhar o crescimento da empresa, porque no atual momento, o software escolhido atende perfeitamente, porém através do crescimento da mesma existe a possibilidade de surgir novas demandas, por isso, será necessário um novo estudo para um momento futuro da empresa.

\section{REFERÊNCIAS}

BARBOSA, M.A. \& ZANARDINI, R.A.D. Iniciação à pesquisa operacional no ambiente de gestão. 2. ed. Curitiba, PR: Intersaberes, 2015.

BLING. Entenda por quê o Bling é o sistema perfeito para você poupar tempo e ganhar dinheiro! Disponível em: < https://www.bling.com.br/home>. Acesso em: 30 de out 2019.

COLANGELO FILHO, Lucio. Implantação de Sistemas ERP (Enterprise Resources Plan- ning): um enfoque de longo prazo. São Paulo: Atlas, 2001.

DAVENPORT, T. H. Putting the enterprise into the enterprise system. Harvard Business Review, p.121-131, jul./aug. 1998.

MENDES, J. V.; ESCRIVÃO FILHO, E. Atualização tecnológica em pequenas e médias empresas: proposta de roteiro para aquisição de sistemas integrados de gestão (ERP). Gestão e Produção, v.14, n.2, p.281-293, maiago.2007.

MORAES, G. D. A.; TERRENCE, A. C. F.; ESCRIVÃO FILHO, E. A Tecnologia da Informação como suporte à gestão estratégica da informação na pequena empresa. Revista de Gestão da Tecnologia e Sistemas de Informação, Vol. 1, No. 1, p 28-44, 2004.

RIBEIRO, Wallace Lima; SANTOS, Marcos dos; GOMES, Carlos Francisco Simões. AHP-TOPSIS-2N Software (v.1). Desenvolvido por meio de uma parceria entre o Institulo Militar de Engenharia (IME), o Centro de Análises de Sistemas Navais (CASNAV) e a Universidade Federal Fluminense (UFF), 2019.

SAATY, T. L. (1980) Analytic Hierarchy Process. New York: McGraw Hill.

SAGE X3. Veja de que modo o Enterprise Management pode ajudar o seu negócio a crescer deforma mais rápida, mas sem perder o controle. Disponível em: < http://www.sagex3.com/pt-br/see_how_animation>. Acesso em: 30 de out 2019.

SANTOS, Marcos dos; MARTHA, Leonardo da Costa; QUINTAL, Renato Santiago; MARTINS, Ernesto Rademaker. Redimensionamento da Linha de Produção de uma Fábrica de Sacos de Lixo Empregando Simulação de Eventos Discretos. Caderno de Cultura e Ciência, Ano XI, v.15, n.1, 2016.

SANTOS, Marcos. Simulação da Operação de um Sistema Integrado de Informações para o atendimento pré-hospitalar de emergência no município do Rio de Janeiro. Dissertação de M.Sc., COPPE/UFRJ, Rio de Janeiro, Brasil, 2013.

SBG. Empresa de Sistema de Gestão ERP - Empresa de Software de Gestão ERP em SP. Disponível em: <http://www.sbg.com.br/empresa-sistema-erp-gestao-empresarial-sp/>. Acesso em: 30 out 2019.

SOUZA, Cezar Alexandre de. Sistemas integrados de gestão empresarial: estudos de caso de implementação de sistemas ERP. Dissertação (Mestrado) - Faculdade de Economia e Administração, Universidade de São Paulo, São Paulo: FEA / USP, 253 p. (2000)

SOUZA, L.; GOMES, C. F. S.; BARROS, A. (2018). Implementation of new Hybrid AHPTOPSIS-2N method in sorting and prioritizing of an it capex project portfolio. International Journal of Information Technology \& Decision Making. 10.1142/S0219622018500207. 